\title{
The Complexity Structures of Conversational Interaction among Participants
}

\author{
Huaizhou Mao \\ Foreign Language Department of Changji University, Changji, Xinjiang, China \\ Email:mhzmed@sina.com \\ Rong Luo \\ Foreign Language Department of Changji University, Changji, Xinjiang, China \\ Email: sbnelr@163.com
}

\begin{abstract}
This paper aims to explore the complexity structures of conversational interaction among participants based on the theory of cooperative principles, turn-taking and topic shifts theoretically to justify the potential possibility of handling the complexity of structures of conversational interaction among participants. Grice's conversational maxims determines the possibility of cooperative principles in conversational interaction, the unpredictability of the turn-taking and the uncertainty of the topic shifts in negotiating topics make the conversational process complex. If speakers probe to develop the awareness of the complexity of structures of conversational interaction among participants in conversational situation, the possibility and unpredictability in spontaneous speech can be realized. However, the paper didn't touch the process of the role analysis, the process of turn-taking analysis, the process of conversational maxims analysis and the topic-shifts in actual conversations based on the transcription.
\end{abstract}

Index Terms - complexity of structures, conversational interaction, conversational maxims, turn-taking, topic shifts

\section{INTRODUCTION}

In pragmatics, the complexity of the structures of conversational interaction among participants is determined by several factors such as the roles of the addresser and addressee, the structure of the conversation as opening conversation, the turning-taking between the addresser and addressee, the topic-shifts, the cooperative principles of the conversation interaction and the conversational settings as well.

An effective conversational interaction must be sufficient with the above conditions. In that case, the complexity of the addresser and addressee's structure of conversational interaction is justified.

The structure of the conversational interaction depicts the outline of a solid conversation where, according to the conversational settings, the alternative structure of conversational interaction (Charles, Fillmore 1981; Jeff \& Feldstein 1970; Sacks, Schegloff \& Fefferson 1974; Schegloff \& Sacks 1973; Hatch \& Long 1980 cited in Carroll 2000 \& H, D. Brown 2002) can be roughly divided into two parts as opening and closing conversation; meanwhile, "conversation are cooperative ventures" (Hatch \& Long 1980, p4). The question is what the rules is that govern conversational interaction; how we get someone's attention; how we initiate topics and how we terminate topics and avoid topics; how a person interrupts, corrects or seeks clarification. The above questions form an area of linguistic competence that every adult native speaker of a language possesses by virtue of conversation rules as the rules of attention getting, topic nomination, topic development and topic termination.

The complexity of structures of conversational interaction among participants depends on the number of the participants as well as the turn-taking in the absence of formal rules. As Clark (1994) pointed out that Conversations often takes place in a context where various types of nonparticipants are also present: (1) supposing Alan asks Barbara a question, Alan and Barbara then are participants in the conversation; (2) supposing Connie has been present during the conversation but is not directly involved in the question. She is a side participant in the conversation; (3) others within earshot are overhearers, who come in varieties; (4) bystanders are those who are openly present but do not participate in the conversation; (5) eavesdroppers are those who listen in without the speaker's awareness. (p4) Many conversational situations bring these roles into play and resort to a variety of strategies when dealing with overhearers, including disclosure, concealment and indifference.

If it is the case that multi-roles played by the participants, "How do speakers avoid 'bumping into' one another in the course of conversations?" According to Sacks et al. (1974), turning-taking during conversational interaction operates by three implicit rules. Turn-taking turns (changes) among the rules of the participants constantly: (1) if the person who speaks first becomes a listener as soon as the person addressed takes $\mathrm{h}$ /she turn in the conversation by beginning to speak; (2) the rules for turn-taking may differ from one community to another as they do from one type of speech event to another (Richards; Platt \& Platt 2000, p.490). 
However, since any statement provides multiple opportunities for topic shifts, it can sometimes seems that the flow of conversation is hardly governed by rules at all especially in a long conversational interactions covering a mumber of topics by confusing "How did we get form there to here?"...

To balance, not only the participants' structure but also the turn-taking eliciting topic shift among different roles of the participants in conversational interaction are based on the conversational settings on whether it is personal settings or institutional settings (Clark 1996; Drew \& Heritage 1992; Clark 1996b; Collins, Warnock \& Passafiume 1975; He, 1994; Heath, 1993 cited in Carroll 2000) to determine the complexity of the participants' structures of conversational interaction.

\section{TheORETICAL ORIENTATIONS}

The theoretical orientations of the complexity of structures of conversational interaction among participants will be formulated by Grice's (1975 cited in He, Ziran 2003) conversational Maxims, Sack's et al. (1974) three implicit rules of turn-taking and Schank's $(1994,1996)$ topic shifts to make a natural institutional discourse analysis by setting the parameters mentioning in the process of analysis in terms of the transcription among the participants at a travel agency in England.

\section{A. Grice's Conversational Maxims}

The theory of conversational maxims put forward by Grice (1967, 1971 cited in Brown 2002 \& Richards; Platt \& Platt 2000) that conversational maxims is "an unwritten rule about conversation which people know and which influences the form of conversational exchanges". The subdivision of Grice's conversational maxims was evolved from the abstract meaning of the notion of conversational implicature, which is "one of the single most important ideas in pragmatics" (Levinson 1983), and which is noticeable for two contributions: "(1) conversational implicatures can help us understand and find satisfactory explanations concerning some difficult linguistic phenomena; (2) the general conversational principles have some effects on the English language such as the formation of certain grammatical structures depending on context and intention."(Levinson 1983 cited in He, Ziran 2003). The important point made by Grice (1975) regarding the theory of implicature is the distinction between what is said and what is implicated: (1) by what is said, it is meant that with some knowledge of the English language, the speaker produces a standard grammatical sentence and this sentence, without any consideration of circumstantial factors, can be understood properly according to its conventional meaning; (2) by what is implied, it is meant that with factors of context and participants the expression used here can carry more meaning that conventionally assigned to the expression. But sometimes, the pragmatic components and mutual shared knowledge must be obtained by way of understanding the conventional meaning of the sentence and the common knowledge, which has something to with one very important factor in the process of generating implicature-the cooperative principle. (p41-58)The cooperative principle noted as Cole \& Morgan (1975) as follows,

Make your conversational contribution such as is required, at the stage at which it occurs, by the accepted purpose or direction of the talk exchange in which you are engaged. (p.41-58)

According to the conversational maxims, there are four detailed and explicit maxims as the quantity maxim, the quality maxim, the relation maxim and manner maxim as follows,

(1) Quantity maxim: (a) make your contribution as informative as is required for the current purpose of the exchange; (b) do not make your contribution more informative than is required.

(2) Quality maxim: try to make your contribution one that is true: (a) do not say what you believe to be false; (b) do not say that for which you lack adequate evidence.

(3) Relation maxim: Be relevant, which means that you say things that are relevant.

(4) Manner maxim: Be perspicuous: (a) avoid obscurity of expression; (b) avoid ambiguity; (c) be brief to avoid unnecessary prolixity and (d) be orderly. (p.41-58)

The above maxims are said to be observed by participants in all speech communities in communicative events but are different from speech community to speech community though, the possible violations as noted by Grice (1975), which means that there are any cases where people do not follow the cooperative principle and maxims as the following four potential to be violated:

(1) The speaker may violate the cooperative principle deliberately but without making the hearer realize it;

(2) The speaker avoid cooperate in an explicit way by telling the hearer that he is unwilling to cooperate;

(3) The speaker may face a dilemma...;

(4) The speaker may deliberately violate one of the maxims or fail to fulfill it. (p.41-58)

In the first case, the speaker doesn't observe the cooperative principle and doesn't tell or indicate to the other participants that he is being uncooperative or less cooperative; in the second case, the speaker makes it explicit that he is not cooperate at the moment and thus no misunderstanding will take place; in the third case, the speaker faces a dilemma by either sacrificing the quantity maxim to hold the quality maxim; the fourth case is the one that can most likely generate conversational implicatures according to Grice, which means that what is said by the speaker differs from what is implicated and the process of which is called "Default Interpretation" by G. Leech (1983 cited in He, Ziran 2003). 


\section{B. Sack's Implicit Rules of Turn-taking}

In the complicated conversational interactions, more than two people are involved so that the single most outstanding fact about conversations is that they run so smoothly in the absence of formal rules. But the question is "How do speakers avoid 'bumping into' one another in the course of conversations?'

According to Sacks et al., (1974) turn-taking during conversations operates by three implicit rules as follows,

(1) The first rule states the current speaker is allowed to select the next speaker. This is often done by directing a question to another person; (2) the second rule is that of self-selection which means if the first rule is not used, another person may speak up; (3) the third rule states that the current speaker can continue, although she or he is not obligated to do so. (p.596-735)

These rules are ordered: "(a) the first one takes priority over the second, who takes priority over the third; (b) if speaker A addresses a comment specifically to B while C starts to talk, B has the floor." This simple set of rules accomplishes a good deal of the organization of conversations. For example, it ensures that most of the conversations take place next turn to a specific individual. The gaps between speakers will tend to be small since the second rule provides an incentive for starting quickly. Thus, although neither turns nor turn length are decided ahead of time, these rules produce an orderly shift from speaker. (Sacks et al. 1974)

In addition, nonverbal behavior between conversational partners also facilitates an orderly transition from one speaker to another. Duncan (1972), after analyzing the signals given to regulate turns in a conversation, defined a turn-yielding signal as the display of one or more of six behavioral cues that appear to indicate a willingness to conclude one's turn as

(1) a drop of pitch; (2) a drawl on the final syllable or final stressed syllable of a final clause; (3) the termination of hand gestures; (4) the use of stereotype expressions such as you know or something, and but uh; (5) a drop loudness and (6) completion of a grammatical classes. (p.283-292)

At times, people wish to continue speaking but fail to find the right word or expression. The "trailing off" of our speech is ambiguous to a listener and may appear to indicate that we are finished. Duncan (1972) also found that, in such cases, speakers resort to what he calls an attempt-suppressing signal, which is the continued use of hand gestures in conjunction with one or more of the turn-yielding cues. When yield cues and attempt-suppressing signals were simultaneously displayed, a listener almost never attempts to take a turn. However, all of this behavior, studied by Beattie, Cutler \& Pearson (1982), is not required for successful conversation because accurate judges by given both video and audio information and by given either video or audio information were the same. But they were unable to distinguish middle and end utterances from a written transcript. Thus, people don't need facial or gestural information to anticipate when a speaker is completing a turn. If turn completion is determined by a number of cues, as Duncan (1972) suggests, then people presumably only need some of the cues to identify the turn-completion. (Duncan 1972)

\section{Schank's Topic Shifts among Participants}

As Grice (1975) noted that "it is not enough merely to take turns with others in conversation. There is a strong social convention to 'be relevant'. In conversation, negotiating topics (topic shifts) means to stick to the topic and trying one's comments to those of the previous speaker."

Schank (1977) argued that there are rules of this kind although it is probably more accurate to say that they govern rather than severely restrict our responses. This is reflected in the observation that some responses are clearly odd; a wide range of "acceptable" responses to any statement is possible.

What the responses seem to have in common is that they are faithful to the topic identified by the speaker, but this is not helpful unless we are able to specify the notion of topic more precisely. Schank (1977) argues that topics in conversation can be defined in terms of the intersection of propositions across sentences...An implication of this definition of topic is that only conversations, not individual sentences or even speaker, have topics as follows,

A: John bought a red car in Baltimore yesterday.

$B$ : I think a red car would be ugly.

C: You mean he is not going to buy my car?

Thus, if speaker A says, "John bought a red car in Baltimore yesterday", speaker B responds to one of these propositions as "I think a red car would be ugly". The intersection of these two sentences is the proposition "the car is red". However, if B's response to this sentence is, "You mean he is not going to buy my car?" This response deals with only one proposition of the preceding sentence as "John bought a car" though, a new topic- the selling of B's car occurs. According to Schank, A has three options at this point:

(1) A may respond to the new topic directly as "No, he didn't like your car"; (2) alternatively, A may refer back to that part of the original topic that got a response as "well, John needed a car in a hurry"; (3) finally, A can make a more generalized response as "It's always difficult to sell a car." (p.421-441)

Although all three types of responses preserve the coherence of the discourse, they do so in different ways: (1) the first response effectively enables B to switch the topic of conversation to B's car; (2) while the second response preserves the initial topic but does so in a way that is relevant to B's remark. Specifically, it continues the discussion of the topic "John bought a car" but focuses on a reason for John's buying the car that is relevant to B's comment; (3) the third response is somewhat ambiguous from a discourse point of view and permits that conversation to go in several 
directions. Non-committal statements are common when there are "lulls" in a conversation.

Since any statement provides multiple opportunities for topic shifts, it can sometimes seem that the flow of conversation is hardly governed by rules at all in long conversation covering numerous topics.

A great deal must be made about what most people regard as appropriate topics and topic shifts in conversations such as Jefferson's (1972) observation of a group of child playing a game called Marco Polo and the studies by Polanyi (1989) by analyzed conversational storytelling and found the differences in interesting ways form conversational discourse in general because the ordinary rules of turn-taking in a conversation of telling a story seem to be temporarily suspended.

Therefore, the best way of characterizing these variations of negotiating topics of conversation is to classify layers of conversations (Clark 1996): "(1) layer 1 is the primary layer of conversational activity-a actual people saying actual things; (2) layer 2 is built on top of layer 1 and represents a different domain or world." Thus, conversational participants shift layers during the course of conversations, creating various problems related to coherence. Each layer has to be coherent, and yet the layers must effectively connect to each other as well. (p.225)

\section{Hatch \& Long's Conversational Structures}

Based on theoretical orientations, not only conversational maxims (Grice 1967, 1971) but also the implicit rules of turn taking (Sacks 1974) and topic shift among participants (Schank, 1977) must be realized through the developmental process of the conversation-conversational structures.

Charles. Fillmore (1981) has stated that "the language of face-to-face conversation is the basic and primary use of language, all others being best described in terms of their derivation from that base ....and this appears to be a reasonable staring point." (p.152)

By comparing conversational with other types of discourse, it will be evident as follows,

TABLE 1

COMPARISON OF FOUR FORMS OF DISCOURSE

\begin{tabular}{|c|c|c|c|c|}
\hline forms & & & & \\
\hline attribute & debate & ceremony & meeting & Conversation \\
\hline Number of people & Two or more & varies & varies & varies \\
\hline topic & fixed & fixed & Potentially fixed & varies \\
\hline Turn order & fixed & fixed & varies & varies \\
\hline Turn length & fixed & varies & varies & varies \\
\hline
\end{tabular}

It can be seen that conversations are the least formal of these types of oral discourse. The number of participant, the topic, the length of a given speaker's contribution, and many other factors are left undecided or decided on the spot. The relaxation of formal rules is one of the prime enjoyments of a good, rich conversation. Thus, by comparing other types of discourse, the structure of conversations become a little bit complex.

Hence, that leads to the five types of conventions that are related to conversations as (1) opening conversations; (2) closing conversations; (3) taking turns, negotiating topics and (4) identifying participants and nonparticipants. From an observer's standpoint, these appear as rules that provide structure to conversational encounters. From a conversational participant's standpoint, these appear as tasks to be addressed during conversational encounters.

Studies of the features of opening conversation by researchers interested in language behavior, language acquisition and social interaction showed that in the vast number of cases, only one person speaks at a time but with the exceptional times by two or more people, which is simultaneous turn instead of simultaneous talking. It is uncommon for listeners to say things like un-hmm and nod their heads while listening to a speaker; these are not attempting to speak but only identify that the listener is following the speaker's train of thought. True points of overlap are most common at turn exchanges when one speaker's turn is ending and another's is beginning (Jeff \& Feldstein 1970; Sack, Schagloff \& Jeffereson 1974). Since neither turn order nor turn length is decided ahead of time, the occurrence of individual variation in the number of turns a given speaker will take and the length of each turn is not surprising. Jeff and Feldstein (1970) reported that the length of a particular speaker's turn was a stable individual characteristic. In contrast, the pauses between vocalizations during a speaker's turn tended to match the pauses of other participants in the conversation. The net effect was to produce a conversation with a certain "rhythm".

Theoretically, the number of possibilities for opening conversation is infinite, in practice we do so in a limited number of ways (Schegloff 1972). Most commonly, we address another person, requesting information, offer information or use some form of stereotyped expression or topic. These serve to get the listener's attention and often lead to stock replies. This quickly establishes the alternation of turns that is central to conversation: A asks a question, B replies, followed by a sequence of the form $A B A B A B$.

Conversations are also at work when we close conversations. Schegloff and Sacks (1973) suggest that one way to end a conversation is to present a pre-closing statement like we-ll, so-o-o, or okay, which signals a readiness to end the conversation. Then listener then may accept the statement with an utterance such as yeah or okay. Alternatively, the listener might bring up another topic and the conversation would continue. (Clark 1994)

Albert and Kessler (1978) list several ways in which we end conversations, including summarizing the content of the conversation, justifying ending contact at this time, expressing pleasure about each other, making reference to the ongoing relationship and planning for future contact and also wishing each other well. They propose that these closing 
moves from a sequence, with items occurring in the order indicated earlier. Their evidence supports such a sequence as the summary statements at the beginning of the ending sequence and well-wishes at the end. The use of reciprocal closing sequence is that

(1) listeners tend to respond to summarize with agreement; (2) to positive statements with similar statements and (3) to well-wishes with good-bye; by presenting one of these closing statements and having one's conversational partner reciprocate, the conversationalists are implicitly negotiating an end to the conversation. (p.541-553)

Specifically, to make a response about the developmental process of conversational structure in the introduction mentioned above, Hatch \& Long (1980) classified four different developmental processes in conversation according to the sequence from opening conversation to closing conversation as follows,

(1) Attention getting: If you wish linguistic production to be functional and to accomplish its intended purpose, you must have the attention of the hearer by both verbal and nonverbal needing to be carefully assimilated by learners.

(2) Topic nomination: Once speakers have secured the hearer's attention, their task becomes one of topic nomination. There are few explicit rules for accomplishing topic nomination in a language. Usually, a person will simply embark on an issue by making a statement or a question that leads to a particular topic. As Grice (1971) noted that the best way to enable the speaker to nominate and maintain a topic of conversation is to confirm certain conversational "maxims" as the quantity maxim, the quality maxims, the relevance and the manner.

(3) Topic development: Once a topic is nominated, participants in a conversation then embark on topic development, using conventions of turn-taking to accomplish various functions of language. Turn-taking is another of these culturally oriented set of rules that require finely tuned perception in order to communicate effectively. Aside from turn-taking itself, topic development or maintenance of a conversation involves clarification, shifting, avoidance and interruption.

(4) Topic termination is an art that even native speakers of a language have difficulty in mastering at times because people commonly experience situations where a conversation has ensured for some time and neither participant seems to know how to terminate it. (Brown 2002, p.236-237)

Thus, the above four developmental process of conversational interaction formulate the dynamic cylinder in the process of the conversational interaction to maintain the complexity of structures of conversational interaction among participants.

\section{CONCLUSION}

Overviewing the theoretical orientations, several factors affect the complexity of structures of the conversational situation among participants. Although Grice's (1975) conversational maxims determines the possibility of cooperative principles in conversational interaction, the unpredictability of the turn-taking (Sacks 1974) and the uncertainty of the topic shifts in negotiating topics (Schank 1994, 1996) make the conversational process complex. Only can we realize the possibility and unpredictability in spontaneous speech of conversational interaction, the awareness of the complexity of structures of conversational interaction among participants can be enhanced in conversational situation.

\section{LimitATIONS}

The survey of the complexity structures of the conversational interaction among participants only triggers the logical hypotheses based on the theoretical orientations. Though it is justified to open up the insight on the complexity of structures of the conversational interaction among participants, what about the process of the role analysis, what about the process of turn-taking analysis, what about the process of conversational maxims analysis and the topic-shifts in actual conversations based on the transcription.

Hence, the ongoing exploration will make a research on the analysis of several factors affecting the complexity of structures of conversational interactions as attached in appendix according to the standards and parameters to further discover the essentiality of the complexity of structures of the conversational interaction. In the present paper, because of the limitation of space and time, it deals only four factors theoretically influencing the complexity of structures of conversational interaction among participants. If interest, much work will be done.

\section{APPENDiX A Discourse ANALYSIS OF REAL-LIFE FEATURES OF THE ACTUAL ENGLISH CONVERSATION}

\section{Instructions:}

The following real-life conversation is quoted from Doing Pragmatics (Peter, Grundy, 1995 \& Edmond, Arnold, P112-114 cited in Gu, Yueguo, 1998:263-266)

Situation:

The conversation took place in a travel agency in England. A is a man, F is a female assistant, MG is a male manager. The following natural conversation is about M-a man, who is going to Edinburgh by plane, talking with a female assistant and male manager at travel agency.

Notes:

(1) (.), (1.5), etc., indicating the length of the pause;

(2) // indicating the beginning of the overlapping utterances;

(3) * indicating the end of the overlapping utterances; 
(4) (( )) indicating something inaudible

\section{Transcriptions:}

M: Can you help me I have to go to Edinburgh (.) somebody told me it was a cheaper to go by plane than by train (.) is that right

$F:$ (1.5) well we are not British Rail agents so I don't know the difference

M: oh I see

F: I can tell you what it is to go to Edinburgh

M: Yes (1.0) by plane

$F$ : by plane

M: yeh (1.7) thanks very much

F: (13.0) well there's a shuttle service (0.4) um (.) sixty pounds one way (2.5) er (2.3) when do you want to go

M: I want to go at the weekend

$F:(0.3)$ what weekend

M: next weekend (3.5) how does that work you just turn up for the shuttle service?

F: (0.8) that might be cheaper then (1.8) that's fifty

M: fifty

F: that's a saver (0.7) bruit it's a stand by

M: a st// andby*

F: $\quad$ //you ha*ve to book it in advance but um (.)

M: are you guaranteed a seat

$F:$ (8.0) I don't think you are

M: so you buy a ticket bef//ore but*

$F$ :

//Ron* with the shuttle saver

$M G:(0.8)$ yeh'

$F:$ um (.) are they guaranteed seats

$M G$ : (3.5) er

F: $\quad$ his is a new one that Marie's just added in here (1.7) oh hang// on see*

MG: $\quad$ //British Airways*

$F:$ see see stop press ((

$M G:$ (0.3) British Airways

F: Yeah

$M G$ : er yeah the flight's a standby guarantee (.) yeah you you turn up and you you've got to er (1.0) if they can't get on one flight they'll put you on the next any of the next two

M: (0.2) and $h / /$ and ${ }^{*}$

F: $\quad$ // $((\quad))^{*}$

M: how often do they go

$M G$ : every two hours

M: every two hours (1.6) so you could wait four hours

$F:$ (1.0) yeh

M: um hum (2.0) and that's fifty pounds one way

$F:$ yes

M: (0.8) and have you got a timetable for

$F$ : not to give out no (0.7) I can tell you the times but I don't

M: ye-es could you tell me hoe often they go Saturdays and coming back on Sundays

F: (13.0) all right (0.3) Saturdays you're going out

M: yeh

$F:$ (1.0) yeh

M: yeh

$F$ : seven-forty nine-forty eleven-forty thirteen-forty

$M:(0.6)$ seven-forty eleven-forty

$F:(0.5)$ seven-forty

$M:$ nine-forty

$F$ : every two hours

$M$ : every two hours on on on forty minutes

$F$ : till (.) nineteen-forty

M: yes (1.3) good

F: and coming back they er (3.4) er (0.4) you're coming back Sunday aren't you

M: Sunday please

$F:$ (2.8) nine-forty eleven-forty

M: ah ah (.) so it's forty either way and it starts at seven-forty on Saturday from London and nine-forty from 
Edinburgh on Sunday(.) until what time on Sunday night

F: same time nineteen-forty

M: nineteen-forty (.) now what happens if you turn up for the nineteen-forty flight and they get you on any of the next two does that mean Monday (1.5) or do they guarantee to do something about it on Sunday night

F: (2.0) I don't know (.)Ron what happens if he wants the last flight (3.7) will they do it like that or don't they allow that

MG: (1.0) what's that

$F$ : what happens if he wants the last fl//ight*

M: $\quad$ //if I* want to come back on the //last flight on the Sunday night*

$F: \quad \quad / /((\quad))$ they don't put* on an extra plane do they

MG: (1.4) well theoretically if it's full they're supposed to put a back-up plane on

M: um hum

$M G$ : in theory (2.1) whether or not it works in particular I don't know

M: (3.0) now if I buy the ticket form you then it costs I pay you a hundred pounds// (.) $n^{*}$

$M G$ : $\quad$ //yes*

M: then I go there and (0.6) $n$ I'm in their hands

$M G$ : that's right sir yes

M: do you know what the rail return (.) weekend return to Edinburgh is by any chance

F: we're not British Rail// agents*

M: $\quad$ // you're* not a//gents I see*

MG: $\quad$ //but I'll give you a rough idea

M: ah ha thank you very much

MG: (12.0) sixty-eight pounds sixty

M: sixty-eight sixty (0.6) good thank you very much (.)I//thin*

$M G$ : $\quad$ //that's* from London sir

M: that's from London (.) either way I've got to get myself (.)

$M G$ : yeh

$M:$ to the right//place*

$M G$ : $\quad$ /yes*

M: yeh I'll think about it

$M G:$ yeh

M: thanks very much that's very helpful (.) bye-bye

\section{REFERENCES}

[1] Albert, S., \& Kessler, S. (1978). Ending social encounters. Journal of experimental social psychology, 14, 541-553.

[2] Brown, H. D. (2002). Principles of Language Learning and Teaching. Beijing: Foreign Language Teaching and Research Press, 235-237.

[3] Carroll, D.W. (2000). Psychology of Language. Beijing: Foreign Language Teaching and Research Press, 222-243.

[4] Duncan, S., Jr. (1972).Some signals and rules for taking speaking turns in conversations. Journal of personality and social psychology, 23, 283-292.

[5] Fillmore, C. J. (1981). Pragmatic and the description of discourse. In P. Cole (Ed.), Radical pragmatics (Vol.3). New York: Academic Press, 143-166.

[6] Grice, H. P. (1975). Logic and conversation. In P. Cole \& J. L. Morgan (Eds.). Syntax and semantics: Speech acts (Vol.3). New York: Seminar, 41-58.

[7] Hatch, Evelyn and Long, Michael. H. (1980). Discourse analysis, what's that? In Larsen-Freeman, 4.

[8] Leech, G. N. (1983). Principles of pragmatics. London: Longman, 102.

[9] Nida, E.A. (1993). Language, Culture and Translating. Shanghai: Shanghai Foreign Language Education Press, 144-148.

[10] Richards, J.C \& Platt \& Platt. (2000). Longman Dictionary of Language Teaching \& Applied_Linguistics. Beijing: Foreign Language Teaching and Research Press, 106-107, 490.

[11] Ralph, Fasold. (2000). The Sociolinguistics of Language. Beijing: Foreign Language Teaching and Research Press. 224.

[12] Ronald, Wardhaugh. (2000). An Introduction to Sociolinguistics. Beijing: Foreign Language Teaching and Research Press, 159.

[13] Sacks, H., E. A. Schegloff, and G. Jefferson. (1974). A simple systematic for the organization of turn-taking for conversation. Language, 50: 696-735.

[14] Schank, R. C. (1977). Rules and topics in conversation. Cognitive science, 1, 421-441.

[15] Thomas, J.A. (1993). Cross-cultural Pragmatic Failure. Applied Linguistics, 4. 58-90.

[16] Yuan Chen. (1983). Sociolinguistics. Shanghai: Xue Lin Press, 88.

[17] Yueguo Gu. (1998). A handbook to Language and linguistics. Beijing: Foreign Language Teaching and Research Press, 237-266. 


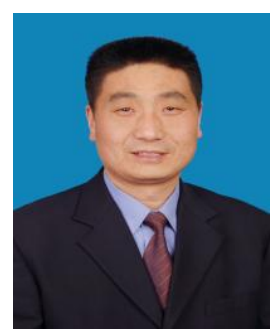

Huaizhou Mao, born in 1966-, Gansu Province of Tianshui City, Instructor, Double M.A Degrees, in Med and Pedagogy, is now teaching in Foreign Language Department of Changji University in Xinjiang Uygur Autonomous Region in China. He is committed to the cause of education in teaching for 26 years, and his research field is the theories of English teaching and curriculum. His main study is concentrated on the Second language acquisition, curriculum development, and empirical researches, especially in the statistics of the Statistic Package of Social Science (SPSS). He published one academic book in 2011, one course book, and nearly 18 articles in the journal of colleges and universities at home and abroad, hosted and took part in four research topics. He is also devoted and is devoting himself in the construction of curriculum such as the methodology of English teaching and the test of English language, and advanced English writing.

Rong Luo, born in 1977-, Xinjiang Uygur Autonomous Region of Changji City, Instructor, M.A Degree, and the director of fundamental English major, in foreign language and applied linguistics, is now teaching in Foreign Language Department of Changji University in Xinjiang Uygur Autonomous Region in China. She is committed to the cause of education in teaching for 12 years, and her research field is functional linguistics. Her main study is concentrated on the interpersonal relationships, and applied linguistics. She published 6 articles in the journal of colleges and universities at home and abroad, hosted and took part in three research topics. She is also devoted and is devoting himself in the general linguistics and listening instructions, and comprehensive English. 